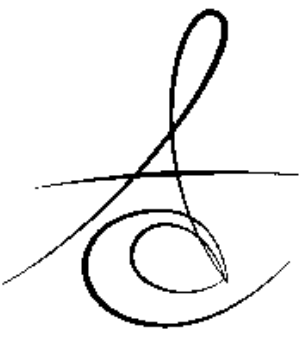

\section{PROFİLAKTİK PAT VE BEYAZLATMA UYGULAMASININ FARKLI KOMPOZİT REZİNLERİN MİKROSERTLİKLERİ ÜZERİNE ETKİSİ}

\section{THE INFLUENCE OF PROPHYLACTIC PASTE AND BLEACHING ON THE MICROHARDNESS OF DIFFERENT COMPOSITE RESINS}

\author{
Arş. Gör. Fatma Dilşad Öz \\ Prof. Dr. Nuray ATTAR*
}

\author{
Dr. Ceren Özge BİÇER* \\ Prof. Dr. Yonca KORKMAZ ${ }^{* * *}$
}

Makale Kodu/Article code: 3463

Makale Gönderilme tarihi: 25.06 .2017

Kabul Tarihi: 19.04.2018

\section{öz}

Amaç: Bu çalışmanın amacl, profilaktik pat ve beyazlatma uygulamalarının ardından farklı tip kompozitlerin mikrosertliklerini değerlendirmektir.

Gereç ve Yöntem: Şeffaf bant ile kapatılmış cam kalıplarda, nanohibrid (GrandioSO) (Grup A), nanodolduruculu akışkan (Filtek Supreme XT Flow) (Grup B) ve nanodolduruculu kompozit (Filtek Ultimate) (Grup C) ile toplam 120 örnek (her bir restoratif materyal için 40 örnek) hazırlanmıştır. Polimerizasyonun ardından tüm örneklere Sof-Lex Disk Sistemi ile bitirme ve polisaj işlemleri uygulanmış ve her bir restoratif materyalin örnekleri 4 gruba ayrılmıştır. Grup 1: $37^{\circ} \mathrm{C}$ distile suda iki hafta bekletilmiştir (kontrol), Grup 2: Proxyt Fine profilaktik pat uygulanmıştır, Grup 3: Pola Office + beyazlatma yapılmıştır, Grup 4: Proxyt Fine profilaktik pat uygulaması + Pola Office+beyazlatma yapılmıştır (toplam 12 grup). Mikrosertlik ölçümleri dijital bir mikrosertlik test cihazı ile gerçekleştirilmiştir (HMV-2, SHIMADZU, Kyoto, Japonya) (yük $500 \mathrm{~g}$; bekleme süresi 15 saniye). Veriler tek yönlü ANOVA test ile analiz edilmiştir. Çoklu karşılaştırmalar Tukey test ile gerçekleştirilmiştir $(p<0.05)$.

Bulgular: GrandioSO materyali için (A), Grup A4, Grup A1'den istatistiksel olarak anlamlı derecede daha düşük mikrosertlik değerleri göstermiştir $(p<0.001)$ ancak Grup $A 1, A 2$ ve $A 3$ arasında fark yoktur $(p=0.51)$. Filtek Supreme XT Flow (B) için 4 grup arasında istatistiksel olarak fark yoktur $(p=0.24)$. Filtek Ultimate materyali için (C), Grup C1 ve C2, Grup C3 ve C4'ten istatistiksel olarak anlamlı derecede daha yüksek mikrosertlik değerleri göstermiştir $(p<0.01)$. Tüm gruplar için, Filtek Supreme XT Flow (B), GrandioSO (A) ve Filtek Ultimate (C) gruplarından anlamlı derecede daha düşük mikrosertlik değerleri göstermiştir $(p<0.01)$.

Sonuç: Profilaktik pat ve beyazlatmanın birlikte uygulanması ya da tek başına beyazlatma işlemi kompozitlerin mikrosertliğini materyalin türüne bağlı olarak olumsuz etkileyebilir.

Anahtar Kelimeler: Kompozit rezinler, diş beyazlatma, diş parlatma.

\section{ABSTRACT}

Aim: The aim of this study was to evaluate the microhardness of different types of composites after application of prophylactic paste and bleaching.

Materials and Methods: A total of 120 specimens (40 specimens for each restorative materials) were fabricated using a nanohybrid (GrandioSO) (Group A), a nanofill flowable (Filtek Supreme XT Flow) (Group B) and a nanofill composite resin (Filtek Ultimate) (Group C) in a plexiglass mold covered with a Mylar strip. After polymerization, all specimens were finished and polished with Sof-Lex (3M ESPE) Polishing disc system and each restorative material specimens were divided into four treatment groups: Group 1: stored in distilled water at $37^{\circ} \mathrm{C}$ for two weeks (control), Group 2: Application of Proxyt Fine Prophylactic paste, Group 3: Bleaching with Pola Office + and Group 4: Application of Proxyt Fine Prophylactic paste + bleaching with Pola Office+ (totally 12 groups). The microhardness measurements were performed using a digital microhardness tester (HMV-2, SHIMADZU, Kyoto, Japan) (load $500 \mathrm{~g}$; dwell time 15 seconds). The data were analyzed using the one-way ANOVA test. Multiple comparison was performed with the Tukey HSD test $(p<0.05)$.

Results: For GrandioSO (A), Group A4 exhibited statistically significant lower microhardness values than Group A1 $(p<0.001)$ but there were no difference among Groups $A 1, A 2$ and $A 3(p=0.51)$. In Filtek Supreme XT Flow (B) there were no statistically significant difference for all 4 groups $(p=0.24)$. In terms of Filtek Ultimate $(C)$, Group C1 and C2 showed statistically significant higher microhardness values than Group C3 and C4 $(p<0.01)$. For all main groups, Filtek Supreme XT Flow (B) exhibited statistically significant lower microhardness values than GrandioSO $(A)$ and Filtek Ultimate $(C)(p<0.01)$.

Conclusion: Application of Prophylactic Paste and bleaching procedure together or bleaching procedure alone may negatively affect the microhardness of composites depending on the type.

Keywords: Composite resins, tooth bleaching, dental polishing.

\footnotetext{
* Hacettepe Üniversitesi, Diş Hekimliği Fakültesi, Restoratif Diş Tedavisi AD, Ankara.

** Sağlık Bakanlığı, Ankara, Türkiye.

*** Texas Üniversitesi, Houston, Texas, ABD.

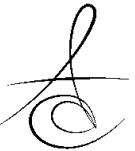




\section{GİRİŞ}

Diş beyazlatma uygulaması, dişlerdeki renklenmelerin giderilmesi için talep gören oldukça popüler bir yöntemdir. Vener, kron ya da kompozit uygulamaları ile karşılaştırıldığında da konservatif bir uygulama şeklidir. $^{1}$

Beyazlatma işlemi için, diş hekimi tarafından muayenehanede yapılan ofis tipi beyazlatma ve hastaların kendileri için özel olarak hazırlanan apareyler içine yerleştirdikleri beyazlatma ajanı ile hekim gözetiminde dişlerini beyazlattıkları ev tipi beyazlatma olmak üzere iki temel yöntem bulunmaktadır. ${ }^{1,2} \mathrm{Bu}$ iki yöntemin maliyetinin yüksek olması nedeniyle geliştirilen alternatif yöntemde (Over The Counter-OTC Sistemler) ise hastalar market ve eczanelerden satın aldıkları ürünlere ilave edilen beyazlatıcı ajanlar ile hekim kontrolü olmadan dişlerini kendileri beyazlatmaktadırlar. $^{3}$

Vital diş beyazlatma uygulamalarında beyazlatıcı ajan olarak hidrojen peroksit ve karbamid peroksit içeren ürünler kullanılmaktadır. \%10'luk karbamid peroksit parçalandığında, \% 3,35 hidrojen peroksit ve \% 6,65 üre oluşur. ${ }^{4}$ Hidrojen peroksit parçalanarak iyonize olduğunda su ve oksijene ayrılır. Açı̆a çıkan oksijen molekülleri diş dokularında yer alan ve dişlerde renklenmelere neden olan organik molekülleri oksidasyon reaksiyonu ile parçalayarak daha küçük moleküller oluşturur. Bu moleküller ışığı yansıtamadıkları için daha açık renkli görünür ve diş renginde beyazlama meydana gelir. ${ }^{3,5}$

Nanokompozitler, inorganik doldurucu partikülleri nano boyutlarda olan restoratif materyallerdir. Partikül boyutu çok küçük olduğu için doldurucunun miktarı oldukça yüksektir. İnorganik doldurucu miktarının artması organik yapıdaki rezin miktarının azalmasını ve polimerizasyon büzülmesinin de daha az gerçekleşmesini sağlar. ${ }^{6}$ Nanokompozitler, sıkışma ve bükülme tipi kuvvetlere ve aşınmaya karşı direnç gibi mekanik özelliklerinin iyi olması nedeniyle hem ön hem arka dişlerde kullanılabilmektedirler. Yüzeylerinin pürüzsüz olması, translusent görünmeleri ve polisajlanabilirliklerinin çok iyi olması da, estetik açıdan oldukça başarılı sonuçlar vermelerine olanak sağlamaktadır. ${ }^{7}$ Akışkan kompozitler, düşük viskoziteleri nedeniyle geleneksel kompozitlere göre kavite duvarlarına daha iyi adaptasyon sağlarlar. Ancak inorganik doldurucu partikül miktarı oldukça düşük olduğu için aşınmaya karşı dirençleri zayıftır. ${ }^{8}$
Kompozit materyallerin yüzey pürüzlülüğü ve sertliği, materyallerin klinik ömrünü etkileyen önemli özellikleridir. Yüzeyin pürüzlü olması plak retansiyonuna neden olarak, restorasyon yüzeyinde renklenme, dişetinde inflamasyon ve sekonder çürük oluşumu ile sonuçlanabilmektedir. ${ }^{8,9} \mathrm{Bu}$ nedenle kompozit restorasyonlar için bitirme ve polisaj işlemleri, hem estetik yönden olumlu sonuçlar alınabilmesi hem de restorasyonların ömrünün uzaması için oldukça önemlidir. Bitirme işlemi, ideal anatomik formun oluşturulması için yapılan şekillendirme, polisaj işlemi ise yüzey pürüzlülüğünün azaltılması işlemidir. Kompozit materyallerinin bitirme ve polisaj işlemleri için, karbid ve elmas frezler, alüminyum oksit partikülleri içeren aşındırıcı diskler, zımparalar ve polisaj patları kullanılmaktadır. ${ }^{6}$ Profilaktik patlar yüzeylerin pürüzsüzleşmesini sağlayarak bakteri adezyonunu engeller. Aynı zamanda restorasyonlardaki mat görünüm ortadan kalkar ve daha doğal parlak bir görünüm elde edilmektedir. Profilaktik pat uygulamasından restorasyonların yüzey özellikleri de etkilenmektedir. Yüzey sertliği ise materyalin aşınmaya karşı direnci ile ilişkilendirilmektedir. Kompozit rezin materyallerde polimerizasyon reaksiyonu ve polimerizasyonun derinliği materyalin sertliğini etkileyen faktörlerdir. ${ }^{10}$

Profilaktik patlar kompozit yüzeylerini daha pürüzsüz bir hale getirdiğinden yüzey özelliklerini, özellikle de yüzey sertlik değerlerini etkileyebilecekleri düşünülmüştür. Yüzey sertlik değerlerinin pürüzlülükten etkilendiği daha önce yapılmış olan bazı çalışmalarda ${ }^{8,10}$ gösterilmiştir. Bu in vitro çalışmanın amacı, kompozit restorasyon yüzeylerinin polisajlanması amaclyla kullanılan profilaktik patın ve ofis tipi beyazlatmanın farklı nanokompozitlerin mikrosertlikleri üzerine etkilerini değerlendirmektir. Çalışma hipotezi profilaktik pat kullanımının beyazlatma sonrası yüzey sertliği değerlerini etkilemeyeceğidir.

\section{GEREÇ VE YÖNTEM}

Çalışmada nanohibrid bir kompozit (GrandioSO, Voco GmbH, Cuxhaven, Almanya) (Grup A), nanodolduruculu akışkan bir kompozit (Filtek Supreme XT Flow, 3M ESPE, St Paul, Minnesota, ABD) (Grup B) ve nanodolduruculu bir kompozit (Filtek Ultimate, 3M ESPE, St Paul, Minnesota, ABD) (Grup C) kullanılmıştır. Polisaj patı olarak Proxyt Fine (Ivoclar Vivadent, Schaan, Liechenstein) ve ofis tipi beyazlatma ajanı 
olarak Pola Office+ (SDI, Bayswater, VIC, Avustralya) kullanılmıştır. Çalışmada kullanılan tüm materyaller Tablo 1'de görülmektedir. Üzerine şeffaf bant yerleştirilen ve her iki tarafı mikroskop camı ile kapatılan cam kalıplarda (10 mm çapında, 2 mm kalınlığında) her bir restoratif materyal için 40 örnek olmak üzere toplam 120 örnek hazırlanmıştır. Restoratif materyaller üretici firmanın önerileri doğrultusunda 20 sn LED ışık kaynağı (Radii Plus, SDI, Bayswater, VIC, Avustralya) $\left(1500 \mathrm{~mW} / \mathrm{cm}^{2}\right)$ ile tek taraftan ve ışık ucu cam kalıba değecek şekilde sabit tutularak polimerize edilmiştir. Işık kaynağının gücü her 10 örnekte bir radyometre (Hilux Light Meter, Benlioğlu Dental, Türkiye) ile kontrol edilmiştir. Polimerizasyonun ardından tüm örneklere Sof-Lex Disk Sistemi (3M ESPE, 3M ESPE, St Paul, Minnesota, ABD) ile bitirme ve polisaj işlemleri uygulanmıştır. Polisaj diskleri, en kalın grenli (50-90 $\mu \mathrm{m})$ olan diskten başlanarak sonrasında sırasıyla orta grenli $(10-40 \mu \mathrm{m})$, ince grenli $(3-9 \mu \mathrm{m})$ ve süper ince grenli $(1-7 \mu \mathrm{m})$ diskler uygulanarak bitirilmiştir. Her disk yüzeye 10 sn süre ile uygulanmıştır. Ardından her bir restoratif materyalin örnekleri rastgele 4 alt gruba ayrılmışıı $(n=10)$. Tüm örnekler ilk olarak $37^{\circ} \mathrm{C}$ distile suda iki hafta bekletilmiştir. Grup 1: Kontrol grubu. Örneklere herhangi bir işlem uygulanmamıştır. Grup 2: Proxyt Fine profilaktik pat, üretici firmanın önerileri doğrultusunda bir lastik yardımıyla uygulanmıştır. Grup 3: Pola Office+ ile beyazlatma yapılmışıı. Beyazlatma işleminde, kompozit örneklerinin üzerine ince bir tabaka beyazlatma ajanı uygulanmış, 8 dakika bekledikten sonra ajan uzaklaştıılarak aynı işlem toplam 4 kez tekrarlanmıştır. Son olarak beyazlatıcı ajan uzaklaştıııdıktan sonra yüzeyler su ile yıkanarak hava ile kurutulmuştur. Grup 4: Proxyt Fine profilaktik pat uygulaması + Pola Office+ ile beyazlatma yapılmışıı. Tüm çalışma grupları ve bu gruplarda uygulanan işlemler Tablo-2'de görülmektedir.

Yüzey mikrosertliklerinin ölçümü için tüm örneklerde ışık ile polimerizasyonun gerçekleştirildiği yüzeylerden dijital bir mikrosertlik test cihazı (HMV-2, SHIMADZU, Kyoto, Japonya) ile ölçüm yapılmışıır (yük $500 \mathrm{~g}$; bekleme süresi 15 saniye). Tüm örneklerin yüzeylerinde 3 farklı noktadan (noktalar birbirlerinden en az $2 \mathrm{~mm}$ uzaktadır) ölçüm yapılarak mikrosertlik değerleri (VHN-Vickers Hardness Number) belirlenmiş ardından ortalamaları alınmıştır.
Tablo 1. Çalışmada kullanılan materyaller

\begin{tabular}{|c|c|c|c|}
\hline MARKA & MATERYAL & İÇERİK & ÜRETİCİ FİRMA \\
\hline GrandioSO & $\begin{array}{l}\text { Nanohibrit } \\
\text { kompozit }\end{array}$ & $\begin{array}{l}\text { BisGMA, BisEMA, } \\
\text { TEGDMA, } \\
\text { kamforokinon, } \\
\text { hidroksitoluen }\end{array}$ & $\begin{array}{l}\text { VOCO, } \\
\text { Schaumburg, Illinois, } \\
\text { ABD }\end{array}$ \\
\hline $\begin{array}{c}\text { Filtek } \\
\text { Supreme } \\
\text { XT Flow }\end{array}$ & $\begin{array}{c}\text { Nanofil } \\
\text { akışkan } \\
\text { kompozit }\end{array}$ & $\begin{array}{l}\text { Metakrilat rezin } \\
\text { monomerleri } \\
\text { BisGMA, TEGDMA ve } \\
\text { BisEMA, dimetakrilat } \\
\text { polimer }\end{array}$ & $\begin{array}{l}\text { 3M ESPE, } \\
\text { St. Paul, MN, ABD }\end{array}$ \\
\hline $\begin{array}{c}\text { Filtek } \\
\text { Ultimate }\end{array}$ & $\begin{array}{c}\text { Nanofil } \\
\text { kompozit }\end{array}$ & $\begin{array}{l}\text { BisGMA, BisEMA, } \\
\text { UDMA, TEGDMA }\end{array}$ & $\begin{array}{l}\text { 3M ESPE, } \\
\text { St. Paul, MN, ABD }\end{array}$ \\
\hline Proxyt Fine & Polisaj patı & $\begin{array}{l}\text { Aşındırıcılar, ksilitol, } \\
\text { florür }\end{array}$ & $\begin{array}{l}\text { IVOCLAR-VIVADENT, } \\
\text { Schaan, Liechtenstein }\end{array}$ \\
\hline $\begin{array}{c}\text { Pola Office } \\
+\end{array}$ & \begin{tabular}{|c|} 
Ofis tipi \\
beyazlatma \\
ajanı
\end{tabular} & $\begin{array}{l}\text { \%37,5 hidrojen } \\
\text { peroksit }\end{array}$ & $\begin{array}{l}\text { SDI, } \\
\text { Victoria, Avustralya }\end{array}$ \\
\hline
\end{tabular}

\section{İstatistiksel Analiz}

Çalışmanın verileri tek yönlü ANOVA test ile analiz edilmiştir. Çoklu karşış̧ı̧ımalarda ise Tukey HSD testi kullanılmışır. İstatistiksel anlamlılık seviyesi $p<0.05$ olarak belirlenmiştir.

\section{BULGULAR}

Tüm çalışma gruplarından elde edilen mikrosertlik değerlerinin ortalamaları ve standart sapmaları Tablo 2'de görülmektedir.

Tablo 2. Tüm grupların mikrosertlik değerleri

\begin{tabular}{|c|c|c|}
\hline Gruplar & Uygulanan İşlemler & $\begin{array}{c}\text { Mikrosertlik Değerleri } \\
(\text { VHN) } \pm \text { Standart Sapma }\end{array}$ \\
\hline Grup A1 & GrandioSO (kontrol) & $136.40^{\mathrm{a}} \pm 16.893$ \\
\hline Grup A2 & $\begin{array}{l}\text { GrandioSO }+ \text { profilaksi } \\
\text { patı }\end{array}$ & $114.17^{\mathrm{a}, \mathrm{b}} \pm 17.806$ \\
\hline Grup A3 & $\begin{array}{l}\text { GrandioSO } \\
\text { beyazlatma }\end{array}$ & $126.50^{\mathrm{a}, \mathrm{c}} \pm 16.662$ \\
\hline Grup A4 & $\begin{array}{l}\text { GrandioSO }+ \text { profilaksi } \\
\text { patı }+ \text { ofis tipi } \\
\text { beyazlatma }\end{array}$ & $103.91^{\mathrm{b}, c, d, e} \pm 20.524$ \\
\hline Grup B1 & $\begin{array}{l}\text { Filtek Supreme XT Flow } \\
\text { (kontrol) }\end{array}$ & $70.13^{f} \pm 11.061$ \\
\hline Grup B2 & $\begin{array}{l}\text { Filtek Supreme XT Flow } \\
+ \text { profilaksi patı }\end{array}$ & $85.12^{\mathrm{d}, \mathrm{f}} \pm 17.271$ \\
\hline Grup B3 & $\begin{array}{l}\text { Filtek Supreme XT Flow } \\
+ \text { ofis tipi beyazlatma }\end{array}$ & $80.43^{d, f} \pm 19.569$ \\
\hline Grup B4 & $\begin{array}{l}\text { Filtek Supreme XT Flow } \\
+ \text { profilaksi patı }+ \text { ofis } \\
\text { tipi beyazlatma }\end{array}$ & $92.83^{\mathrm{b}, \mathrm{f}} \pm 27.747$ \\
\hline Grup C1 & Filtek Ultimate (kontrol) & $125.28^{\mathrm{a}, \mathrm{e}} \pm 17.033$ \\
\hline Grup C2 & $\begin{array}{ll}\text { Filtek Ultimate } & + \\
\text { profilaksi patı } & \end{array}$ & $145.10^{\mathrm{a}} \pm 18.345$ \\
\hline Grup C3 & $\begin{array}{l}\text { Filtek Ultimate }+ \text { ofis tipi } \\
\text { beyazlatma }\end{array}$ & $69.49^{f} \pm 19.188$ \\
\hline Grup C4 & $\begin{array}{l}\text { Filtek Ultimate }+ \\
\text { profilaksi patı }+ \text { ofis tipi } \\
\text { beyazlatma }\end{array}$ & $91.52^{b, f} \pm 15.168$ \\
\hline
\end{tabular}

*Aynı harflerle belirtilen üst simgeler istatistiksel olarak benzerdir. 
GrandioSO materyalinin tüm gruplarının (GA1+ $\mathrm{GA2}+\mathrm{GA} 3+\mathrm{GA} 4$ ) toplam ortalama mikrosertlik değeri $119.69 \pm 21.315$, Filtek Supreme XT Flow materyalinin tüm gruplarının (GB1+GB2+GB3+GB4) ortalama mikrosertlik değeri $82.13 \pm 20.795$, Filtek Ultimate materyalinin tüm gruplarını (GC1+GC2+GC3+GC4) ortalama mikrosertlik değeri ise $107.85 \pm 34.089^{\prime}$ dur.

GrandioSO materyali için, profilaktik pat ve beyazlatma ajanının birlikte uygulandığı Grup A4, Grup A1 grubuna göre istatistiksel olarak anlamlı derecede düşük mikrosertlik değerleri gösterirken $(p<0,01)$, Grup A1, A2 ve A3 arasında anlamlı bir fark görülmemiştir $(p=0.51)$.

Filtek Supreme XT Flow materyali için her 4 grupta da (Grup B1, B2, B3, B4) istatistiksel olarak benzer mikrosertlik değerleri ölçülmüştür $(p=0.24)$.

Filtek Ultimate materyali için tek başına beyazlatmanın uygulandığı Grup C3 ve polisaj patı ile beyazlatmanın birlikte uygulandığı Grup C4, C1 ve C2'ye göre istatistiksel olarak anlamlı derecede düşük mikrosertlik değerleri göstermiştir $(p<0.01)$.

Tüm kompozit materyalleri ele alındığında, Filtek Supreme XT Flow materyalinde (B) diğer materyallere göre daha düşük mikrosertlik değerleri görülmüştür (Filtek Supreme XT Flow< Filtek Ultimate< GrandioSO, $\mathrm{p}<0.05$ ) (Tablo 2).

\section{TARTIŞMA}

Kompozit restorasyonlarda bitirme ve polisaj işlemleri ile pürüzsüz bir yüzey elde edilmesinin restorasyonun klinik ömrünü uzattığı bilinmektedir. Yapılan çalışmalar ve teknolojide yaşanan gelişmeler ile yeni bitirme ve polisaj sistemleri geliştirilse de tamamen pürüzsüz yüzeyler elde edilememektedir. Yüzey pürüzlülüğünün, bitirme ve polisaj işlemlerinin yanı sıra restoratif materyalin doldurucu içeriği, doldurucu boyutu ve mikrosertliği gibi mekanik özellikleri ile de doğrudan ilişkili olduğu bilinmektedir. ${ }^{11,12}$

Bir materyalin mikrosertliği, yüzeyin aşınmaya karşı direncini göstermektedir. Mikrosertlik, materyalin dayanıklılığ, elastisitesi, plastisitesi ve viskozitesi ile ilişkilidir. ${ }^{13}$ Restoratif materyalin sertliğinin yüksek olması restorasyonun klinik ömrünün uzun olmasını belirleyen en önemli kriterlerden biridir. Materyalin mikrosertliğindeki azalma, restorasyonun başarısızlığına neden olarak yenilenmesini gerektirebilir. ${ }^{14}$ Erdemir ve ark. ${ }^{15}$ yaptıkları in vitro çalışmada bitirme ve polisaj işlemlerinin 3 farklı kompozit materyalin mikrosertlikleri üzerine etkisini incelemişler ve iki farklı polisaj sistemi ile yapılan polisaj işleminin tüm materyallerin mikrosertliğinde artışa neden olduğunu bildirmişlerdir. Bizim çalışmamızın sıfır hipotezi reddedilmiştir. Beyazlatma ajanı ile birlikte kullanımında profilaktik patlar farklı kompozitlerin yüzey sertliği değerlerinde değişikliğe neden olmuştur. Ancak bu in vitro çalışmada, kulIanılan profilaktik pat ile yapılan polisaj işlemi materyallerin hiçbirinin mikrosertliğinde tek başına anlamlı bir değişiklik oluşturmamışı $(p>0,05)$.

Beyazlatma işleminin restoratif materyallerin özellikleri üzerine etkilerini inceleyen birçok çalışma yapılmışıı. Bu çalışmalarda, farklı konsantrasyonlarda, farklı tip beyazlatma ajanlarının farklı restoratif materyallerin yüzey pürüzlülüğü, mikrosertliği, yüzey parlakığı, rengi, monomer salımı ve diş dokularına bağlanmaları gibi özelliklerinde yarattığı değişiklikler incelenmiştir. ${ }^{7,16-19}$ Bu çalışmaların birçoğunda yüzey özelliklerindeki değişikliklerin materyale bağı olduğu bildirilmiştir. Wang ve ark. ${ }^{16}$ beyazlatıcı jellerin, kompozitlerin yüzey pürüzlülükleri üzerine etkilerini değerlendirdikleri çalışmalarında, beyazlatmanın süresine ve materyalin türüne bağlı olarak yüzey pürüzlülüğünde değişiklikler oluştuğunu bildirmişlerdir. Wattanapayungkul ve ark. ${ }^{17}$ beyazlatma işleminin kompozit rezinlerde yüzey pürüzlülüğünü anlamlı derecede arttırdığını ancak bu artışın plak retansiyonuna neden olacak seviyede olmadığını, bu nedenle de bu sonucun klinik olarak bir anlamı olmadığını bildirmişlerdir. Moraes ve ark. ${ }^{7}$ farklı konsantrasyonlarda peroksit içeren beyazlatma ajanlarının kompozitlerin pürüzlülüğü üzerine etkilerini değerlendirdikleri çalışmalarında benzer sonuçlara ulaşmışlardır. Yüzey pürüzlülüğündeki artışın mikrosertlikteki azalma ile doğrudan ilişkili olduğu düşünülmekte, bu nedenle beyazlatıcı ajanların restoratif materyallerin mikrosertliğinde oluşturdukları değişiklikler de birçok çalışmada değerlendirilmektedir. Bizim çalışmamızda profilaktik pat kullanımı ile bu pürüzlülüklerin giderilerek, daha yüksek sertlik değerleri elde edilip edilemeyeceği araştırımıştır. Çalışmadaki nanohibrit ve nanofil kompozit gruplarında, profilaktik pat uygulaması ile birlikte beyazlatma ajanı kullanılması sonucu sertlik değerlerindeki azalma olduğu düşünülmüştür.

AlQahtani ${ }^{13}, \quad \% 10^{\prime}$ luk karbamid peroksit beyazlatma ajanını nanofil kompozit, siloran bazlı kompozit ve hibrit kompozitlerin mikrosertliğinde

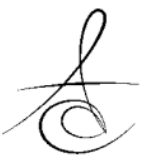


azalmaya neden olduğunu bildirmiştir. Bu sonuçlar bizim çalışmamız ile örtüşmektedir. Lima ve ark. ${ }^{20}$ $\% 16$ 'ık karbamid peroksitin hibrit kompozit rezinin mikrosertliğini azaltırken \%35'lik hidrojen peroksitin herhangi bir etki oluşturmadığını rapor etmişlerdir. Polydorou ve ark. $^{21}$ yaptıkları in vitro çalışmada, \%38'lik hidrojen peroksit içeren beyazlatma ajanının, 6 farklı estetik restoratif materyalin hiçbirinde mikrosertlikte azalmaya neden olmadığı sonucuna varmışlardır. Bununla birlikte bizim çalışmamızda nanofil akışkan kompozit grubu ve nanohibrit kompozit grubu tek başına beyazlatma ajanı uygulamasından etkilenmezken, nanofil kompozit grubunda beyazlatma sonrası mikrosertlik değerlerinde azalma olmuştur.

$\mathrm{Bu}$ çalışmada kullanılan ofis tipi beyazlatma ajanı \%37,5 hidrojen peroksit içermektedir. Hidrojen peroksit oksidasyon reaksiyonu ile oldukça reaktif olan serbest radikallerin oluşumuna neden olur. Bu serbest radikallerin birleşerek moleküler oksijen ve su oluşturduğu ve bu kimyasal sürecin kompozit materyallerde hidrolitik yıkıma neden olduğu bildirilmektedir. Kompozitlerin sertliğindeki azalma bu kimyasal süreç ile ilişkilendirilmektedir. ${ }^{22}$ Serbest radikallerin yüksek enerjileri doldurucu partiküller ve rezin matriks arasını olumsuz etkiler ve organik yapının su emilimini arttırmaktadır. Doldurucu partiküllerin bütünlüğü bozularak materyaller sertliklerini kaybetmektedir. ${ }^{21}$

Profilometrik analizler yapan çalışmalar hem ev tipi hem de ofis tipi beyazlatma ajanlarının kompozitlerin yüzey özelliklerini değiştirdiğini tespit etmiştir. Ancak yüksek konsantrasyonlu beyazlatma ajanları daha önemli zedelenmelere neden olmaktadır. ${ }^{23-26}$ Klinik olarak daha hızı sonuç veren ve yüksek oranda hidrojen peroksit içermesi nedeniyle bu çalışmada ofis tipi beyazlatma ajanları incelenmiştir.

Ev tipi beyazlatma ajanlarının (\%10-16 karbamid peroksit) kompozitlerin yüzey mikrosertliği üzerine etkileri tartışmalıdır. Bazı çalışmalar yüzey sertliğinde azalma rapor ederken ${ }^{27}$, bazı çalışmalar belirgin bir değişim gözlememiştir ${ }^{28,29}$, bununla birlikte artış tespit eden çalışmalar olmuştur. ${ }^{21}$ Akışkan kompozitlerin ise daha düşük doldurucu içeriğinin olması profilaktik pat ile, beyazlatma ajanlarından daha az etkilenmelerine neden olmuştur. ${ }^{30}$

Metakrilat bazlı bir kompozit ve siloran bazlı bir kompozitin farklı konsantrasyonlarda ev tipi beyazlatma ajanı uygulanmaları sonrasında, mikrosertliklerinin karşılaştıııldığı bir çalışmanın sonuçlarına göre, farklı konsantrasyonlar mikrosertlik değerlerini etkilemezken, siloran bazlı kompozitin mikrosertlik değerlerinde beyazlatma sonrası artış gözlenmiştir. ${ }^{31}$ Bununla birlikte, Bahari ve ark. ${ }^{32}$ son zamanlarda yaptıkları bir çalışmada siloran bazlı kompozitlerin beyazlatma sonrası mikrosertliklerinin azaldığını rapor etmiştir.

Ek olarak, düşük viskoziteli bir polisaj patının beyazlatma sonrası mikrosertlik değerlerini inceleyen in vitro bir çalışma, polisaj öncesi ve sonrasında mikrosertlik değerleri arasında bir fark olmadığını göstermiştir. ${ }^{33}$ Aynı çalışma kullanılan \%45'lik ofis tipi carbamid peroksitin yüzey mikrosertliğini etkilemediği ancak \%10'luk ev tipi beyazlatma ajanının yüzey mikrosertlinde azalmaya neden olduğunu tespit etmiştir. Bu durumun ev tipi beyazlatma ajanının günde 8 saat uygulanması ile ilgili olabileceği düşünülmüştür. ${ }^{33}$

$\mathrm{Bu}$ in vitro çalışmada uygulanan beyazlatma işlemi, nanohibrit ve nanofil kompozitlerin mikrosertliğinde profilaktik pat uygulaması ile birlikte anlamlı bir azalmaya neden olurken, nanofil akışkan kompozitte istatistiksel olarak anlamlı olmamakla birlikte profilaktik pat uygulaması ile artışa sebep olmuştur.

\section{SONUÇLAR}

Bu çalışmada kullanılan nanofil akışkan kompozit en düşük mikrosertlik değerlerini göstermiştir. Profilaksi patı ile yapılan polisaj işlemi, materyallerin mikrosertliğinde tek başına anlamlı bir değişiklik oluşturmamıştır. Çalışmada kullanılan \%37,5 hidrojen peroksit içeren beyazlatma ajanı ile yapılan beyazlatma işlemi hem tek başına ve hem de profilaktik pat ile birlikte uygulandığında kompozit materyalin türüne bağlı olarak mikrosertliğe etki etmiştir. Mikrosertlik değerlerindeki düşüşte \%37,5 hidrojen peroksitin etkisi olduğu gözlemlenmiştir.

Fatma Dilşad Öz: ORCID ID: 0000-0002-7450-723X

Ceren Özge Biçer : ORCID ID: 0000-0002-8195-4847

Nuray Attar: ORCID ID: 0000-0002-6050-3051

Yonca Korkmaz: ORCID ID: 0000-0001-9543-6453

\section{KAYNAKLAR}

1. Heymann HO. Tooth whitening: facts and fallacies. Br Dent J 2005;19:514.

2. Gurgan S, Alpaslan T, Kiremitci A, Cakir FY, Yazici E, Gorucu J. Effect of different adhesive systems and laser treatment on the shear bond strength of bleached enamel. J Dent 2009;37:527-34. 
3. Marshall K, Berry TG, Woolum J. Tooth whitening: current status. Compend Contin Educ Dent 2010;31:486-92.

4. Josey AL, Meyers IA, Romaniuk K, Symons AL. The effect of a vital bleaching technique on enamel surface morphology and the bonding of composite resin to enamel. J Oral Rehabil 1996;23:244-50.

5. Joiner A. The bleaching of teeth: a review of the literature. J Dent 2006;34:412-9.

6. Chen $\mathrm{MH}$. Update on dental nanocomposites. J Dent Res 2010;89:549-60.

7. Moraes RR, Marimon JL, Schneider LF, Correr Sobrinho L, Camacho GB, Bueno M. Carbamide peroxide bleaching agents: effects on surface roughness of enamel, composite and porcelain. Clin Oral Investig 2006;10:23-8.

8. Ozel E, Korkmaz Y, Attar N, Karabulut E. Effect of one-step polishing systems on surface roughness of different flowable restorative materials. Dent Mater J 2008;27:755-64.

9. Jefferies SR. The art and science of abrasive finishing and polishing in restorative dentistry. Dent Clin North Am 1998;42:613-27.

10. Gordan VV, Patel SB, Barrett AA, Shen C. Effect of surface finishing and storage media on bi-axial flexure strength and microhardness of resin-based composite. Oper Dent 2003;28:560-7.

11. Choi MS, Lee YK, Lim BS, Rhee SH, Yang HC. Changes in surface characteristics of dental resin composites after polishing. J Mater Sci Mater Med 2005; 16:347-53.

12. Strassler HE. Polishing composite resins. J Esthet Dent 1992;4:177-9.

13. AlQahtani MQ. The effect of a $10 \%$ carbamide peroxide bleaching agent on the microhardness of four types of direct resin-based restorative materials. Oper Dent 2013;38:316-23.

14. Okada K, Tosaki S, Hirota K, Hume WR. Surface hardness change of restorative filling materials stored in saliva. Dent Mater 2001;17:34-9.

15. Erdemir U, Sancakli HS, Yildiz E. The effect of onestep and multi-step polishing systems on the surface roughness and microhardness of novel resin composites. Eur ] Dent 2012;6:198-205.

16. Wang L, Francisconi LF, Atta MT, Dos Santos JR, Del Padre NC, Gonini A, Jr., et al. Effect of bleaching gels on surface roughness of nanofilled composite resins. Eur J Dent 2011;5:173-9.
17. Wattanapayungkul $P$, Yap AU, Chooi KW, Lee MF, Selamat RS, Zhou RD. The effect of home bleaching agents on the surface roughness of tooth-colored restoratives with time. Oper Dent 2004;29:398-403.

18. Omrani LR, Farjadfar S, Pedram $P$, Sadray $S$, Kamangar SSH, Chiniforoush N. Effect of laserassisted and conventional in-office bleaching on monomer release from microhybrid and nanohybrid composite. Laser Ther 2017;26:89-96.

19. Lago M, Mozzaquatro LR, Rodrigues $C$, Kaizer MR, Mallmann $A$, Jacques LB. Influence of bleaching agents on color and translucency of aged resin composites. J Esthet Restor Dent 2017;29:368-77.

20. Lima DA, De Alexandre RS, Martins AC, Aguiar FH, Ambrosano GM, Lovadino JR. Effect of curing lights and bleaching agents on physical properties of a hybrid composite resin. J Esthet Restor Dent 2008;20:266-73.

21. Polydorou O, Hellwig E, Auschill TM. The effect of at-home bleaching on the microhardness of six esthetic restorative materials. J Am Dent Assoc 2007; 138:978-84.

22. Polydorou O, Monting JS, Hellwig E, Auschill TM. Effect of in-office tooth bleaching on the microhardness of six dental esthetic restorative materials. Dent Mater 2007;23:153-8.

23. Bailey SJ, Swift EJ Jr. Effects of home bleaching products on composite resins. Quintessence Int 1992;23:489-94.

24. Bowles WH, Lancaster LS, Wagner MJ. Reflectance and texture changes in bleached composite resin surfaces. J Esthet Den;1996;8:229-33.

25. Turker SB and Biskin T. Effect of three bleaching agents on the surface properties of three different esthetic restorative materials. J Prosthet Dent 2003;89:466-73.

26. Wattanapayungkul P, Yap AU. Effects of in-office bleaching products on surface finish of toothcolored restorations. Oper Dent 2003;28:15-9.

27. Turker SB, Biskin T. The effect of bleaching agents on the microhardness of dental aesthetic restorative materials. J Oral Rehabil 2002;29:65761.

28. Garcia-Godoy F, Garcia-Godoy A, Garcia-Godoy. FEffect of bleaching gels on the surface roughness, hardness, and micromorphology of composites. Gen Dent 2002;50:247-50. 
29. Nathoo SA, Chmielewski MB, Kirkup RE. Effects of colgate platinum Professional toothwhitening system on micro- hardness of enamel, dentin, and composite resins. Compend Contin Educ Dent Suppl 1994;17:627-30.

30. Bayne SC, Thompson JY, Swift EJ Jr, Stamatiades $P$, Wilkerson $M$. A characterization of firstgeneration flowable composites. J Am Dent Assoc 1998;129:567-77.

31. Esmaeili B, Abolghasemzadeh F, Gholampor A, Daryakenari G. The effect of home bleaching carbamide peroxide concentration on the microhardness of dental composite resins. Gen Dent 2018;66:40-4.

32. Bahari M, Savadi Oskoee S, Mohammadi N, Ebrahimi Chaharom ME, Godrati M, Savadi Oskoee A. Effect of different bleaching strategies on microhardness of a silorane-based composite resin. J Dent Res Dent Clin Dent Prospects 2016;10:21319.

33. Yikilgan İ, Kamak H, Akgul S, Ozcan S, Bala O. Effects of three different bleaching agents on microhardness and roughness of compositesample surfaces finished with different polishing techniques. J Clin Exp Dent 2017;9:460-5.

\section{Yazışma Adresi}

Fatma Dilşad ÖZ

Hacettepe Üniversitesi, Diş Hekimliği Fakültesi, Restoratif Diş Tedavisi Anabilim Dalı.

Sıhhiye, 06100, Ankara, TÜRKİYE.

Tel: 03123052270

Faks: 03123113438

e-mail: dilsadoz@yahoo.com 